\title{
Survival of Patients with Small Cell Lung Carcinoma in Taiwan
}

\author{
Yu-Hsuan Kuo a-c Zhong-Zhe Lin ${ }^{a, c}$ Yen-Yun Yang ${ }^{d}$ Yu-Yun Shao ${ }^{a, c}$ \\ Wen-Yi Shau ${ }^{e}$ Raymond N.C. Kuo ${ }^{d}$ James Chih-Hsin Yang ${ }^{c, h}$ Mei-Shu Laid, f, g \\ ${ }^{a}$ Department of Oncology, National Taiwan University Hospital Yun-Lin Branch, Yunlin, ${ }^{b}$ Department of Oncology, \\ E-Da Hospital, Kaoshiung, 'Department of Oncology, and ${ }^{\mathrm{d} C}$ Center for Comparative Effectiveness Research, \\ Clinical Trial Center, National Taiwan University Hospital, e Division of Health Technology Assessment, Center for \\ Drug Evaluation, ${ }^{\mathrm{f}}$ Taiwan Cancer Registry, and ${ }^{\mathrm{g}}$ Institute of Preventive Medicine, College of Public Health, and \\ ${ }^{h}$ Graduate Institute of Oncology and Cancer Research Center, National Taiwan University, Taipei, Taiwan, ROC
}

\section{Key Words}

Small cell lung cancer · Prognosis - Best supportive care

\begin{abstract}
Background: Small cell lung cancer (SCLC) is the most aggressive form of lung cancer. The prognosis for SCLC patients remains unsatisfactory despite advances in chemotherapy. In this study, we sought to clarify the prognosis and treatment patterns of patients with SCLC. Methods: A cohort comprising all patients diagnosed with SCLC between January 2004 and December 2006 was assembled from the Taiwan Cancer Database. Patients were followed up until December 31, 2009, to determine overall survival. Patient survival was estimated using the Kaplan-Meier method, and Cox's proportional hazard model was used to determine the relationship between prognostic factors and median survival time. Results: Among the 1,684 patients diagnosed with SCLC, 1,215 (72\%) were diagnosed with extensive-stage disease and 469 (28\%) with limited-stage disease. Most of the patients were male (90\%). The median survival duration of patients with limited-stage and extensive-stage SCLC was 10.3 months and 5.6 months, respectively. For limited-stage patients, surgery, chemotherapy, and combined chemotherapy and radiotherapy resulted in better survival than best
\end{abstract}

\section{KARGER}

Fax +4161306 1234 E-Mail karger@karger.ch www.karger.com
(C) 2012 S. Karger AG, Basel 0030-2414/12/0821-0019\$38.00/0

Accessible online at:

www.karger.com/ocl supportive care (HR 0.20, p < 0.001; HR 0.61, p < 0.001, and HR $0.37, p<0.001$, respectively). For extensive-stage patients, male gender was significantly associated with a poor prognosis (HR 1.45, p<0.001) and chemotherapy was shown to improve overall survival more effectively than best supportive care (HR 0.37, p < 0.001). Conclusion: For limitedstage SCLC patients, surgery, chemotherapy, and combined chemotherapy and radiotherapy improved survival compared to best supportive care. Extensive-stage SCLC patients benefited more from chemotherapy treatment than from best supportive care.

Copyright $\odot 2012$ S. Karger AG, Basel

\section{Introduction}

Small cell lung cancer (SCLC) accounts for approximately $15 \%$ of all bronchogenic carcinomas reported in the literature [1]. SCLC is the most aggressive form of pulmonary cancer and, without treatment, the median survival ranges from 2 to 4 months [1-4]. Unlike other cell types of lung cancer, SCLC is both chemosensitive and

Y.-H. Kuo and Z.-Z. Lin contributed to this work equally.
Mei-Shu Lai

Institute of Preventive Medicine, College of Public Health

National Taiwan University

5F. No. 17, Hsu Chow Road, Taipei 10055, Taiwan (ROC)

Tel. +88623366 8018, E-Mail mslai@ntu.edu.tw 
radiosensitive; however, most patients have a dismal prognosis. Roughly $60-70 \%$ of patients have extensivestage disease at the time of diagnosis, from which point the median ranges of survival for limited and extensive stages are 15-20 months and 8-13 months, respectively [5-11]. Regardless of stage, the current prognosis for patients with SCLC is unsatisfactory despite the advances made in diagnosis and therapy in recent decades.

The aim of our study was to analyze the prognosis and treatment patterns associated with SCLC patients in Taiwan. In addition, we also analyzed (1) the survival of SCLC patients in various geographic locations and (2) the impact of various forms of treatment on survival.

\section{Method}

\section{Study Cohort and Data Collection}

The study cohort comprised patients registered in the Taiwan Cancer Database (TCDB), which covers all hospitals in Taiwan (more than 50 beds). All patients diagnosed with SCLC between January 2004 and December 2006 were enrolled into this study. Eligibility for this study required the following: (1) histologically or cytologically confirmed SCLC and (2) age $>18$ years. Patients were excluded if they died on the day of diagnosis, had been diagnosed with other forms of cancer, or had undergone surgery for extensive-stage SCLC. Patients who failed to transform from TNM stage to Veteran's Administration Lung Group 2-stage were also excluded [12]. Abstraction of full medical records was conducted to obtain demographics (age and sex), tumor pathology, staging, and the types and timing of treatment. All patients were actively followed up until December 31, 2009.

\section{Determination of Stage}

In this study, the Veteran's Administration Lung Group 2-stage classification scheme was used to define the extent of disease in patients with SCLC as follows: (1) limited-stage disease was defined as disease confined to the ipsilateral hemithorax, which can be safely encompassed within a tolerable radiation field, and (2) extensive-stage disease was defined as disease beyond the ipsilateral hemithorax, which may include malignant pleural or pericardial effusion or hematogenous metastases. A number of patients were classified according to the American Joint Committee on Cancer (AJCC) staging system, 6th edition, rather than the Veteran's Administration Lung Group 2-stage classification. We transformed the TNM stage of these patients to limited or extensive stage according to these rules: (1) if $\mathrm{N}=0-2$ or $\mathrm{M}=0$, then it was regarded as limited stage; (2) If $\mathrm{N}=3$ or $M=1$, then it was regarded as extensive stage.

\section{Determination of Timing and Types of Treatment}

All treatment modalities refer to first-line treatment. The chemotherapy and radiotherapy regimen and dosage depended on the discretion of doctors. The combined chemotherapy and radiotherapy period was defined from the first day of radiotherapy, 30 days prior to the first day of chemotherapy, until 180 days after. We defined the 'early thoracic radiation' period from 30 days pri- or to until 104 days after the first day of chemotherapy and the 'late thoracic radiation' period between 105 and 180 days after the first day of chemotherapy.

Statistical Analysis

This study employed $\chi^{2}$ or Fisher's exact tests for categorical data and $t$ tests for continuous measures to compare the differences between study groups. Overall survival was estimated using the Kaplan-Meier method, and a log-rank test was used to compare differences between groups. Cox's proportional hazard model was used to analyze the hazard ratio (HR) with a $95 \%$ confidence interval (95\% CI) for the effects of gender, cancer stage, treatment, and age on overall survival. $\mathrm{p} \leq 0.05$ was considered statistically significant. Statistical analysis was performed using SAS ${ }^{\circledR}$, version 9.2 (SAS Institute, Inc., Cary, N.C., USA).

\section{Results}

A total of 1,774 patients fulfilled the study criteria. The reasons for the exclusion of patients are as follows: 1 patient died on the day of diagnosis, 86 patients were diagnosed with forms of cancer other than small cell carcinoma, and 2 patients had received surgery for extensivestage disease. Another 90 patients were excluded for failing to transform TNM stage to Veteran's Administration Lung Group 2-stage. A total of 1,684 patients with SCLC were included in the final analysis.

Patient characteristics are listed in table 1. Among 1,684 patients, 1,215 (72\%) patients had extensive-stage disease, and 469 (28\%) patients had limited-stage disease. A strong predominance of males (1,510 patients, $90 \%)$ was observed. No differences were noted in terms of sex or age among limited-stage or extensive-stage patients. In the limited-stage group, 184 (39\%) patients received chemotherapy, 142 (30\%) patients received combined chemotherapy and radiotherapy, and $92(20 \%)$ patients received best supportive care. In the extensive-stage group, 659 (54\%) patients received chemotherapy, 170 (14\%) patients received combined chemotherapy and radiotherapy, and 349 (29\%) patients received best supportive care. Patients with limited- and extensive-stage SCLC had a median survival of 10.3 and 5.6 months, respectively.

Table 2 shows the Cox regression analysis for patients with limited- and extensive-stage disease. Among patients with limited-stage disease, gender was not correlated with prognosis ( $\mathrm{HR} 1.14, \mathrm{p}=0.421$ ). Compared to best supportive care, patients receiving surgery, chemotherapy, or combined chemotherapy and radiotherapy showed significantly better overall survival (HR 0.20, p < 0.001; HR 0.61, p < 0.001, and HR 0.37, p < 0.001, respectively). By contrast, patients receiving radiotherapy alone 
showed survival equivalent to receiving best supportive care. Age is a poor prognostic factor (HR 1.36, $\mathrm{p}=0.003$ ). Among patients with extensive-stage disease, male gender was associated with a poor prognosis (HR 1.45, p < 0.001). Chemotherapy was associated with a better survival prognosis (HR $0.37, \mathrm{p}<0.001)$ than best supportive care. Age is a poor prognostic factor for extensive-stage patients (HR 1.30, p < 0.001).

Only $18 \%$ of these patients over 70 years of age with limited-stage SCLC received combined chemotherapy and radiotherapy, $43 \%$ received chemotherapy alone, and a high proportion $(27 \%)$ of patients only received best supportive care. Limited-stage patients receiving combined chemotherapy and radiotherapy showed a similar median survival, irrespective of age. By contrast, among limited-stage patients, older patients only receiving chemotherapy had a significantly shorter median survival than younger patients (fig. 1)

\section{Discussion}

According to the SEER database, the proportion of SCLC (among all forms of lung cancer) decreased from $17.26 \%$ in 1986 to $12.95 \%$ in 2002 . However, among patients with SCLC, the proportion of women with SCLC increased from $28 \%$ in 1973 to $50 \%$ in 2002 [1]. In our analysis, the proportion of women with SCLC was approximately $10 \%$. Because over $95 \%$ of cases of SCLC are caused by exposure to tobacco, the incidence rate mirrors smoking patterns [13]. One possible explanation for the lower proportion of women with SCLC in Taiwan (compared to Western countries) is the lower prevalence of smoking among women in Taiwan.

Surprisingly, the median survival of limited-stage and extensive-stage SCLC patients in Taiwan is remarkably shorter than that encountered in Western countries. In Western countries, the median ranges of survival (from the time of diagnosis) for limited- and extensive-stage diseases are 15-20 months and 8-13 months, respectively $[3,5,6,14]$. However, in our analysis, the median survival of patients with limited- and extensive-stage SCLC in Taiwan is only 10.3 months and 5.6 months, respectively. Possible explanations include (1) undertreatment in Taiwan and (2) differences in ethnicity. For limitedstage SCLC, current treatment standards should include chemotherapy with concurrent radiotherapy beginning in the first or second cycle. According to our analysis, only $30 \%$ of limited-stage patients received combined chemotherapy and radiotherapy; however, for those
Table 1. Patient characteristics

\begin{tabular}{|c|c|c|c|c|}
\hline & \multicolumn{2}{|c|}{ Limited stage } & \multicolumn{2}{|c|}{ Extensive stage } \\
\hline & $\mathrm{n}$ & $\%$ & $\mathrm{n}$ & $\%$ \\
\hline Total & 469 & 27.85 & 1,215 & 72.15 \\
\hline \multicolumn{5}{|l|}{ Sex } \\
\hline Male & 418 & 89.13 & 1,092 & 89.88 \\
\hline Female & 51 & 10.74 & 123 & 10.17 \\
\hline \multicolumn{5}{|l|}{ Treatment } \\
\hline Chemotherapy & 184 & 39.23 & 659 & 54.15 \\
\hline Radiotherapy & 27 & 5.76 & 37 & 3.05 \\
\hline Chemo-radiotherapy & 142 & 30.28 & 170 & 13.99 \\
\hline Surgery & 24 & 5.12 & - & - \\
\hline BSC & 92 & 19.62 & 349 & 28.72 \\
\hline \multicolumn{5}{|l|}{ Age group, years } \\
\hline $18-49$ & 23 & 4.90 & 64 & 5.27 \\
\hline $50-69$ & 181 & 38.59 & 495 & 40.74 \\
\hline $70+$ & 265 & 56.50 & 656 & 53.99 \\
\hline \multicolumn{5}{|l|}{ Age, years } \\
\hline Mean (SD) & 69.5 & $(10.68)$ & 69.0 & $(10.40)$ \\
\hline Median (range) & 71 & $(33-97)$ & 71 & $(27-93)$ \\
\hline \multicolumn{5}{|l|}{ Follow-up, months } \\
\hline Mean (SD) & 15.2 & $(15.39)$ & 8.4 & $(10.53)$ \\
\hline Median (range) & 10.3 & $(0.07-67.3)$ & 5.6 & $(0.07-70.9)$ \\
\hline \multicolumn{5}{|l|}{ Death $^{1}$} \\
\hline All cause for death & 424 & 90.41 & 1,178 & 96.95 \\
\hline
\end{tabular}

BSC $=$ Best supportive care

${ }^{1}$ The follow-up end date was December 31, 2009.

receiving standard treatment, the median survival was similar to that encountered in Western countries (limited stage: 15.15 months receiving combined radiotherapy and chemotherapy; extensive stage: 7.57 months receiving chemotherapy) (online supplementary tables 1, 2; for all online suppl. material, see www. karger.com/doi/10.1159/000335084).

We also noted a high proportion (19.62\%) of limitedstage patients only receiving best supportive care. The reason may be that the age of patients or the location of hospitals is associated with a higher proportion of supportive care. Older patients and those treated in hospitals in southern Taiwan tend to receive supportive care (online suppl. table 3). Online supplementary figure 1 shows the age distribution of patients receiving best supportive care and other forms of treatment. Most patients (77\%) receiving best supportive care were over 70 years of age; thus, it can be assumed that old age is the main reason that these patients only received best supportive care.

Online supplementary table 4 shows the patient distribution by hospital. A total of 469 limited-stage patients 
Table 2. Cox's proportional hazard analysis for overall survival of SCLC patients

\begin{tabular}{|c|c|c|c|c|c|}
\hline \multirow[t]{2}{*}{ Variable } & & \multirow[t]{2}{*}{ HR } & \multicolumn{2}{|c|}{$95 \% \mathrm{CI}$} & \multirow[t]{2}{*}{$\mathrm{p}$ value } \\
\hline & & & lower & upper & \\
\hline \multicolumn{6}{|c|}{ Limited-stage SCLC } \\
\hline \multirow[t]{2}{*}{ Sex } & female & reference & & & \\
\hline & male & 1.14 & 0.83 & 1.55 & 0.421 \\
\hline \multirow[t]{5}{*}{ Treatment } & best supportive care & reference & & & \\
\hline & chemotherapy & 0.61 & 0.47 & 0.80 & $<0.001$ \\
\hline & chemo-radiotherapy & 0.37 & 0.28 & 0.49 & $<0.001$ \\
\hline & surgery & 0.20 & 0.12 & 0.34 & $<0.001$ \\
\hline & radiotherapy & 0.81 & 0.52 & 1.26 & 0.345 \\
\hline \multirow[t]{2}{*}{ Age, years } & $18-69$ & reference & & & \\
\hline & $70+$ & 1.36 & 1.11 & 1.67 & 0.003 \\
\hline \multicolumn{6}{|c|}{ Extensive-stage SCLC } \\
\hline \multirow[t]{2}{*}{ Sex } & female & reference & & & \\
\hline & male & 1.45 & 1.20 & 1.76 & $<0.001$ \\
\hline \multirow[t]{3}{*}{ Treatment } & best supportive care & reference & & & \\
\hline & chemotherapy & 0.37 & 0.32 & 0.42 & $<0.001$ \\
\hline & non-chemotherapy & 0.61 & 0.43 & 0.87 & 0.006 \\
\hline \multirow[t]{2}{*}{ Age, years } & $18-69$ & reference & & & \\
\hline & $70+$ & 1.30 & 1.15 & 1.46 & $<0.001$ \\
\hline
\end{tabular}

were included in this analysis. Among them, 92 patients received best supportive care. It was found that institution A had a markedly higher proportion of patients receiving best supportive care. Furthermore, institution A has three branch hospitals in Taiwan, and all three branches have a higher proportion of patients receiving best supportive care than other similar hospitals. We also analyzed the age distribution among limited-stage patients treated in different institutions (online suppl. table 5). In most institutions, except branch 2 of institution A, patients under 70 years of age received at least one modality treatment, and patients over 70 years of age received best supportive care. However, in branch 2 of institution $\mathrm{A}$, the mean age of six patients receiving best supportive care was 67.7 years, which is lower than that observed in other hospitals. The reasons for these discrepancies may require further investigation.

Moreover, we attempted to determine whether ethnicity is a prognostic factor in SCLC patients. Asian ethnicity is considered a favorable prognostic factor in NSCLC patients; however, there remains a paucity of literature concerning the significance of ethnicity in the survival outcome of SCLC. Studies have indicated that Asian SCLC patients have survival outcomes similar to those found in the West; however, no direct comparisons have been made $[15,16]$.
The role of combined chemotherapy and radiotherapy in the treatment of limited-stage SCLC was established decades ago. The CALGB trial in the late 1980s demonstrated that $90 \%$ of patients treated with chemotherapy alone failed locally [17]. Several meta-analyses have also provided data supporting thoracic radiotherapy in limited-stage SCLC patients [18-20]. A meta-analysis in 1992 showed that combined modality therapy resulted in a $14 \%$ reduction in the death rate and a $5.4 \%$ improvement in 3-year survival compared with chemotherapy alone [18]. In our analysis, combined chemotherapy and radiotherapy resulted in a $13 \%$ improvement in 3-year survival compared to chemotherapy alone (data not shown).

In addition, a number of papers have mentioned that the sequence of chemotherapy and radiotherapy is also a prognostic factor in limited-stage patients [21-23]. We further define the 'early thoracic radiation' period from 30 days prior to until 104 days after the first day of chemotherapy and the 'late thoracic radiation' period between 105 and 180 days after the first day of chemotherapy.

Based on these definitions, we analyzed the overall survival of limited-stage patients receiving early thoracic radiation and late thoracic radiation. We observed no difference in overall survival between these two groups of patients (online suppl. table 6 and fig. 2). 
Fig. 1. Interaction plot for treatment modality by age in the overall survival of patients with limited-stage SCLC. Limitedstage patients receiving combined chemotherapy and radiotherapy had similar median survival times irrespective of age (years) (log-rank $=0.4533$ ). By contrast, older patients receiving only chemotherapy had a significantly shorter median survival than younger patients (log-rank = 0.0159).

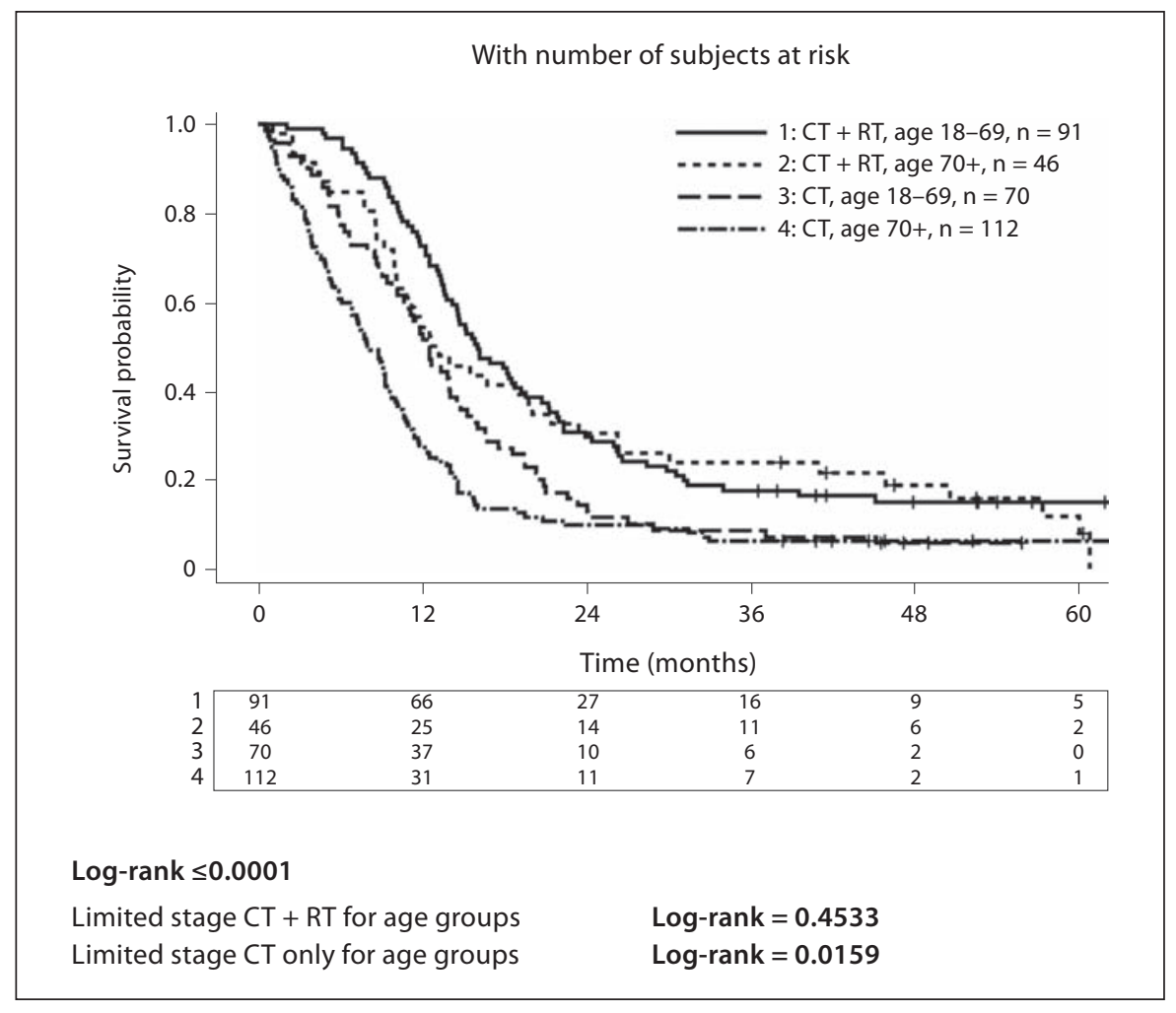

We also observed that surgery improved survival among limited-stage patients. Because most patients presented with unresectable disease at the time of diagnosis, we hypothesize that most of the patients receiving firstline surgery had TMN stage I or II disease. According to current SCLC guidelines, chemotherapy alone is the standard treatment for extensive-stage patients [24]. Our results also demonstrate that chemotherapy improved survival outcomes in extensive-stage patients.

In this study, an advanced patient age was associated with significantly worse outcomes in patients with extensive-stage SCLC as well as those with limited-stage SCLC. Actually, advanced age has not been identified as an adverse prognostic factor in patients with SCLC in most [2527], but not all, studies [28-30]. This study analyzed treatment patterns among patients 70 years and older, observing that the median survival with multimodality therapy was similar to that of younger individuals. This implies that older patients with good performance status should receive the same multimodality treatment as younger patients.

The limitations of this study include a lack of detailed information related to the treatment course, as we were only able to analyze the relationship between first-line treatment and prognosis. We were unable to determine whether patients had received prophylactic cranial irradiation, which has been shown to increase overall survival in limited-stage or extensive-stage SCLC. In addition, we were unable to obtain information related to performance status, smoking history, or laboratory results and were thus unable to explain the shorter median survival among patients in this study compared to those in Western countries.

In summary, this study presented the largest observational population-based cohort study related to the survival of SCLC patients in Taiwan. For limited-stage SCLC patients, surgery or combined chemotherapy and radiotherapy improved survival rates over those achieved with best supportive care. Extensive-stage SCLC patients also benefited more from chemotherapy treatment than from best supportive care.

\section{Acknowledgments}

This study was supported by a grant from the Bureau of Health Promotion, Department of Health, Taiwan, (Taiwan Cancer Registry Project) and by grants from the Science and Technology Unit, Department of Health, Taiwan, (DOH99-TD-B-111-001, DOH100-TD-B-111-001). 


\section{References}

1 Govindan R, Page N, Morgensztern D, Read W, Tierney R, Vlahiotis A, Spitznagel EL, Piccirillo J: Changing epidemiology of small-cell lung cancer in the United States over the last 30 years: analysis of the surveillance, epidemiologic, and end results database. J Clin Oncol 2006;24:4539-4544.

$\checkmark 2$ Lebitasy MP, Hedelin G, Purohit A, Moreau L, Klinzig F, Quoix E: Progress in the management and outcome of small-cell lung cancer in a French region from 1981 to 1994 . Br J Cancer 2001;85:808-815.

-3 Janne PA, Freidlin B, Saxman S, Johnson DH, Livingston RB, Shepherd FA, Johnson BE: Twenty-five years of clinical research for patients with limited-stage small cell lung carcinoma in North America. Cancer 2002; 95:1528-1538.

$\checkmark 4$ Laskin JJ, Erridge SC, Coldman AJ, D’Yachkova Y, Speers C, Westeel V, Hislop TG, Olivotto IA, Murray N: Populationbased outcomes for small cell lung cancer: impact of standard management policies in British Columbia. Lung Cancer 2004;43:716.

$\checkmark 5$ Seifter EJ, Ihde DC: Therapy of small cell lung cancer: a perspective on two decades of clinical research. Semin Oncol 1988;15:278299.

6 Osterlind $\mathrm{K}$, Hansen HH, Hansen M, Dombernowsky P, Andersen PK: Long-term disease-free survival in small-cell carcinoma of the lung: a study of clinical determinants. J Clin Oncol 1986;4:1307-1313.

-7 Albain KS, Crowley JJ, Livingston RB: Longterm survival and toxicity in small cell lung cancer: expanded southwest oncology group experience. Chest 1991;99:1425-1432.

$>8$ Lassen U, Osterlind K, Hansen M, Dombernowsky P, Bergman B, Hansen HH: Longterm survival in small-cell lung cancer: posttreatment characteristics in patients surviving 5 to $18+$ years - an analysis of 1,714 consecutive patients. J Clin Oncol 1995;13: 1215-1220.

9 Tai P, Tonita J, Yu E, Skarsgard D: Twentyyear follow-up study of long-term survival of limited-stage small-cell lung cancer and overview of prognostic and treatment factors. Int J Radiat Oncol Biol Phys 2003;56: 626-633.

10 Rawson NS, Peto J: An overview of prognostic factors in small cell lung cancer: a report from the Subcommittee for the Management of Lung Cancer of the United Kingdom Coordinating Committee on Cancer Research. Br J Cancer 1990;61:597-604.
1 Paesmans M, Sculier JP, Lecomte J, Thiriaux J, Libert P, Sergysels R, Bureau G, Dabouis G, Van Cutsem O, Mommen P, Ninane V, Klastersky J: Prognostic factors for patients with small cell lung carcinoma: analysis of a series of 763 patients included in 4 consecutive prospective trials with a minimum follow-up of 5 years. Cancer 2000;89:523-533.

12 Micke P, Faldum A, Metz T, Beeh KM, Bittinger F, Hengstler JG, Buhl R: Staging small cell lung cancer: Veterans Administration Lung Study Group versus International Association for the Study of Lung Cancer what limits limited disease? Lung Cancer 2002;37:271-276.

13 Wingo PA, Ries LA, Giovino GA, Miller DS Rosenberg HM, Shopland DR, Thun MJ, Edwards BK: Annual report to the nation on the status of cancer, 1973-1996, with a special section on lung cancer and tobacco smoking. J Natl Cancer Inst 1999;91:675-690.

14 Fry WA, Menck HR, Winchester DP: The National Cancer Data Base report on lung cancer. Cancer 1996;77:1947-1955

$>15$ Mohan A, Goyal A, Singh P, Singh S, Pathak AK, Bhutani M, Pandey RM, Guleria R: Survival in small cell lung cancer in India: prognostic utility of clinical features, laboratory parameters and response to treatment. Indian J Cancer 2006;43:67-74.

16 Toh CK, Hee SW, Lim WT, Leong SS, Fong KW, Yap SP, Hsu AA, Eng P, Koong HN, Agasthian T, Tan EH: Survival of small-cel lung cancer and its determinants of outcome in Singapore. Ann Acad Med Singapore 2007;36:181-188.

17 Perry MC, Eaton WL, Propert KJ, Ware JH, Zimmer B, Chahinian AP, Skarin A, Carey RW, Kreisman H, Faulkner C, et al: Chemotherapy with or without radiation therapy in limited small-cell carcinoma of the lung. N Engl J Med 1987;316:912-918.

18 Pignon JP, Arriagada R, Ihde DC, Johnson DH, Perry MC, Souhami RL, Brodin O, Joss RA, Kies MS, Lebeau B, et al: A meta-analysis of thoracic radiotherapy for small-cell lung cancer. N Engl J Med 1992;327:16181624.

19 Pignon JP, Arriagada R: Role of thoracic radiotherapy in limited-stage small-cell lung cancer: quantitative review based on the literature versus meta-analysis based on individual data. J Clin Oncol 1992;10:1819-1820.

20 Warde P, Payne D: Does thoracic irradiation improve survival and local control in limitedstage small-cell carcinoma of the lung? A meta-analysis. J Clin Oncol 1992;10:890-895.

-21 Murray N, Coy P, Pater JL, Hodson I, Arnold A, Zee BC, Payne D, Kostashuk EC, Evans WK, Dixon P, et al: Importance of timing for thoracic irradiation in the combined modality treatment of limited-stage small-cell lung cancer - the National Cancer Institute of Canada Clinical Trials Group. J Clin Oncol 1993;11:336-344.
22 Takada M, Fukuoka M, Kawahara M, Sugiura T, Yokoyama A, Yokota S, Nishiwaki Y, Watanabe K, Noda K, Tamura T, Fukuda H, Saijo N: Phase III study of concurrent versus sequential thoracic radiotherapy in combination with cisplatin and etoposide for limited-stage small-cell lung cancer: results of the Japan Clinical Oncology Group Study 9104. J Clin Oncol 2002;20:3054-3060.

-23 Spiro SG, James LE, Rudd RM, Trask CW, Tobias JS, Snee M, Gilligan D, Murray PA, Ruiz de Elvira MC, O’Donnell KM, Gower NH, Harper PG, Hackshaw AK: Early compared with late radiotherapy in combined modality treatment for limited disease small-cell lung cancer: A London Lung Cancer Group multicenter randomized clinical trial and meta-analysis. J Clin Oncol 2006; 24:3823-3830.

24 Johnson BE, Crawford J, Downey RJ, Ettinger DS, Fossella F, Grecula JC, Jahan T, Kalemkerian GP, Kessinger A, Koczywas M, Langer CJ, Martins R, Marymont MH, Niell HB, Ramnath N, Robert F, Williams CC Jr: Small cell lung cancer clinical practice guidelines in oncology. J Natl Compr Canc Netw 2006;4:602-622.

25 Siu LL, Shepherd FA, Murray N, Feld R, Pater J, Zee B: Influence of age on the treatment of limited-stage small-cell lung cancer. J Clin Oncol 1996;14:821-828.

26 Jorgensen LG, Osterlind K, Genolla J, Gomm SA, Hernandez JR, Johnson PW, Lober J, Splinter TA, Szturmowicz M: Serum neuron-specific enolase (S-NSE) and the prognosis in small-cell lung cancer (SCLC): a combined multivariable analysis on data from nine centres. Br J Cancer 1996;74:463467.

27 Jara C, Gomez-Aldaravi JL, Tirado R, Meseguer VA, Alonso C, Fernandez A: Small-cell lung cancer in the elderly - is age of patient a relevant factor? Acta Oncol 1999; 38:781-786.

28 Osterlind K, Andersen PK: Prognostic factors in small cell lung cancer: multivariate model based on 778 patients treated with chemotherapy with or without irradiation. Cancer Res 1986;46:4189-4194.

29 Albain KS, Crowley JJ, LeBlanc M, Livingston RB: Determinants of improved outcome in small-cell lung cancer: an analysis of the 2,580-patient Southwest Oncology Group data base. J Clin Oncol 1990;8:1563-1574.

30 Spiegelman D, Maurer LH, Ware JH, Perry MC, Chahinian AP, Comis R, Eaton W, Zimmer B, Green M: Prognostic factors in smallcell carcinoma of the lung: an analysis of 1,521 patients. J Clin Oncol 1989;7:344-354. 